\title{
Teoria e Política nas Relações Internacionais: algumas reflexões pessoais*
}

\section{Theory and Policy in International Relations: some Personal Reflections}

Stephen M. Walt ${ }^{1}$

\footnotetext{
* A Revista Universitas: Relações Internacionais agradece imensamente a contribuição do Professor Stephen Walt a esta edição, bem como do Professor Mark J. Redmond, Editor-Chefe do Yale Journal of International Affairs, que cedeu os direitos autorais da Revista, além do Professor Mark Langevin, da University of Maryland, que realizou a interlocução entre autor e Editor para viabilizar esta publicação.

Originalmente publicado no Yale Journal of International Affairs (September 2012).

A Revista recebeu a autorização de tradução e republicação do artigo em 21/03/2013.

Tradução de Renata de Melo Rosa. Revisão de tradução de Mark Langevin.

1 Stephen Walt é Professor do International Security Program, Belfer Center for Science and International Affairs da Harvard Kennedy School. Email: Stephen_Walt@harvard.edu
}

\section{Resumo}

$\mathrm{O}$ artigo discute as diversas relações existentes entre teoria e política, sobretudo no imbricamento de seus campos profissionais. Analisa o baixo impacto da teoria das Relações Internacionais nas decisões de política externa, as tensões metodológicas existentes entre os dois campos e discute os motivos pelos quais estes processos ocorrem. Ao final, propõe soluções para que haja mais diálogo e interação entre a academia e os políticos.

Palavras-chave: Teoria de Relações Internacionais. Política. Relação entre academia e política.

\begin{abstract}
The article discusses the various relationships between theory and policy, especially as they overlap and are woven throughout the related professional fields of International Relations and foreign policymaking. Analyzes the little influence that International Relations theory has over foreign policy making, sources of methodological tensions and divergence between the two fields, and discusses why they occur. The article concludes by proposing solutions to promote greater dialogue and interaction between academia and policymakers.
\end{abstract}

Keywords: International Relations Theory. Politics. Relationship between academia and politics. 


\section{Introdução}

A maioria dos cientistas sociais gostaria de pensar que seus trabalhos ajudam a resolver problemas importantes. Para os intelectuais das relações internacionais, certamente não há falta de questões para se discutir: conflitos étnicos e religiosos, gestão da frágil economia mundial, terrorismo global, mudança climática, propagação de armas de destruição em massa, a crise do Euro, etc. A lista é interminável. Nesta ordem global cada vez mais complexa e ainda contenciosa, alguém pode pensar que a experiência acadêmica sobre assuntos internacionais seria uma mercadoria altamente valorizada. Seria de se esperar ver teóricos trabalhando sem parar para conceber soluções práticas para os vários problemas do mundo real e exercendo papéis proeminentes nos debates públicos sobre política externa. Até o momento, este não parece ser o caso da maioria deles. Ex-políticos reclamam que a academia é "ou irrelevante ou inacessível... fechada dentro do círculo de discussões acadêmicas esotéricas" e um intelectual recentemente foi acusado "que os intelectuais estão muito mais focados em si mesmos do que no mundo real ... A pesquisa está se tornando cada vez mais obscurantista" (NEWSOM, 1995-1996; MEAD, 2010).

Esta situação não é a que eu previ quando decidi obter um título de $\mathrm{PhD}$ em Ciência Política na primavera de 1976, quando estudava em um Programa de Intercâmbio da Universidade de Stanford, em Berlim. Minha graduação foi em Relações Internacionais e eu estava dividido entre fazer o Mestrado em Ciência Política ou o bem trilhado e seguro caminho do Direito. Uma palestra sobre a era dos intelectuais em Weimar, ministrada pelo historiador Gordon Craig inclinou a balança: Craig argumentou que muitos intelectuais alemães tinham se retirado da vida pública durante este período, julgando serem os políticos muito corruptos e sórdidos para suas esclarecidas participações. A abdicação dos intelectuais abriu as portas para o Nazismo ${ }^{2}$. Jovem e idealista (alguns diriam ingênuo), eu decidi obter um $\mathrm{PhD}$ e tentar trazer
2 Alguns dos materiais desta palestra foram posteriormente incorporados em Craig (1978, p. 479-495). a academia para ajudar nas importantes questões de políticas públicas ${ }^{3}$.

Passaram-se quase trinta anos que eu recebi meu título de $\mathrm{PhD}$. Naquela época, eu estava convencido que a pesquisa acadêmica sistemática poderia descobrir e verificar eternamente as verdades sobre a política internacional e a política externa e uma vez que aquelas descobertas fossem feitas, uma agradecida comunidade política rapidamente as absorveria e adotaria a fórmula certa. Com o passar do tempo, adquiri tanto um profundo respeito pelos limites do que a ciência social pode realizar como uma enorme admiração pela imprevisibilidade da comunidade política para fundamentar seu discurso, especialmente nos Estados Unidos. Mesmo se os intelectuais fossem capazes de produzir análises mais convincentes - elas mesmas uma proposição discutível - capazes de superar os interesses arraigados que moldam o que os políticos decidem fazer, não seria fácil.

Este tema pode ser rastreado através do meu próprio trabalho, embora eu não tenha moldado a minha trajetória acadêmica de maneira consciente. Meu trabalho inicial sobre formação de alianças (por exemplo, The Origins of Alliances, 1987) foi destinado a resolver alguns quebra-cabeças teóricos que estavam no coração dos debates políticos recorrentes sobre o uso da força na política externa norte-americana (WALT, 1987). Argumentei que a alegação de que os Estados estavam inclinados a fazer alinhamentos (isto é, se aliar com poderes fortes e/ ou ameaçadores) foi frequentemente usada para justificar o uso da força e de maneira majoritária, para manter a credibilidade norte-americana e evitar que os aliados deserdassem para o bloco soviético. Por outro lado, se os Estados estivessem inclinados a construir um equilíbrio contra as ameaças, então a credibilidade norte-americana não seria tão importante e as dispendiosas guerras na periferia não seriam necessárias. A intervenção norte-ame-

\footnotetext{
3 Eu tive a felicidade de estudar com Alexander George (meu orientador de monografia de graduação) e Kenneth Waltz (meu orientador de dissertação). Seus estilos intelectuais são completamente diferentes: George trabalhou por indução (intuitivamente) e estava descrente das grandes generalizações ao passo que Waltz trabalhou dedutivamente e com premiada parcimônia. Ainda ambos viram a teoria das ciências social como uma ferramenta para informar políticas mais inteligentes e de mais sucesso e nunca acreditaram que a academia pudesse ser uma comunidade isolada divorciada das preocupações do mundo real.
} 
ricana também foi justificada pela percebida necessidade de evitar que os governos de esquerda ganhassem poder, baseada na crença que tais regimes estavam ideologicamente dispostos a se aliar com Moscou. Minha pesquisa mostrou que o equilíbrio era muito mais frequente que $o$ alinhamento, e minha conclusão política inicial foi que pelo fato de os Estados Unidos desfrutarem de uma enorme vantagem geopolítica sobre a União Soviética, ele não necessitaria intervir no desenvolvimento mundial por razões de credibilidade e poderia, no mais das vezes, ter uma visão muito mais tranquila de seus aparatos de segurança. O livro foi bem recebido pela academia mundial e atraiu uma modesta atenção nos círculos políticos, mas é difícil discernir qualquer efeito direto na política externa norte-americana.

Meu trabalho subsequente (WALT, 1996) aplicou a teoria do "equilíbrio de ameaças" para explicar por que as revoluções domésticas levam ao aumento de uma espécie de "competição de seguranças" e um altíssimo risco de guerra (WALT, 1996). Novamente, começou com um quebra-cabeça político: por que os políticos norte-americanos ficaram tão alarmados com a maioria das revoluções domésticas e por que Washington manteve relações tão fracas com os revolucionários russos, chineses, cubanos, iranianos e muitos outros? Eu achei que as revoluções tornariam o cálculo do equilíbrio de poder mais difícil, desencadeando equívocos mútuos que fazem o uso da força parecer tanto necessário quanto atrativo e frequentemente conduzem a altíssimos níveis de corrida por segurança e um risco crescente de guerra. Argumentei que as estratégias de "negligência benevolente" estavam suscetíveis para amortecer estes efeitos e permitir que os Estados Unidos (e outros países) contivessem os efeitos dos levantes revolucionários com menos custos e menos riscos. Qualquer que seja o mérito destes argumentos, a evidência de seu impacto político foi de leve a não existente.

Em Taming American Power: the Global Response to US Primacy (WALT, 2005a), procurei explicar como aliados e inimigos estavam respondendo a uma posição incomum de dominação que os Estados Unidos estavam gostando de seguir após o fim da União Soviética (WALT, 2005a). Por que por muito tempo os aliados norte-americanos estiveram alarmados pela supremacia norte-americana e quais estratégias os aliados fizeram e os adversários empregaram para desviar o poder norte- -americano ou explorá-lo para seus próprios fins? Apesar de não limitado a conceitos puramente realistas, este trabalho ainda assim refletiu uma sensibilidade basicamente realista: mesmo que a política norte-americana estivesse motivada por objetivos nobres, outros Estados poderiam não tomar a benevolência norte-americana como certa. Para reduzir a oposição à supremacia norte-americana e garantir que os aliados chave dos Estados contribuíssem com uma parcela justa dos encargos da segurança coletiva, defendi uma grande estratégia de "equilíbrio internacional” que reduziria a marca de militarização global dos Estados Unidos e evitaria guerras longas e caras em áreas de importância estratégica periférica. O caso para esta prescrição foi ainda mais forte na esteira da crise financeira de 2007 e das fracassadas campanhas no Iraque e no Afeganistão, mas foram estes eventos que empurraram os Estados Unidos em direção a uma estratégia maior e mais inteligente e não a minha eloquência anterior.

Finalmente, meu trabalho com John Mearsheimer sobre o impacto do lobby israelense foi tanto um afastamento de uma análise puramente realista e outra que em nada reflete nossas raízes realistas compartilhadas (MEARSHEIMER; WALT, 2006; 2007). Em nossa visão, o "relacionamento especial" entre Estados Unidos e Israel não está presente em qualquer interesse estratégico de Estado a longo prazo e é assim inconsistente com a base de princípios realistas ${ }^{4}$. Para os realistas, portanto, o pródigo e incondicional apoio que os Estados Unidos fornecem a Israel é uma anomalia que precisa ser explicada. Nós argumentamos que este apoio é contabilizado principalmente pela influência de um conjunto particularmente poderoso de grupos de interesse nos Estados Unidos. O livro foi um Best seller e ajudou a abrir um longo debate sobre esta questão, mas tanto a influência do lobby como

4 Estritamente falando, este argumento se encontra fora do paradigma realista, mas não é inconsistente com os argumentos realistas. Os realistas sustentam que a pressão da anarquia encoraja os Estados a enfatizar interesses claramente nacionais porque os Estados irão pagar um preço se tiverem outros objetivos. Mas os realistas também reconhecem que muitos Estados poderosos podem possuir objetivos não realistas se eles estiverem dispostos a pagar este preço, como os Estados Unidos tem feito ao dar a Israel um quase apoio incondicional. 
o próprio "relacionamento especial" se mostraram pouco afetados até agora 5 .

O que estas e outras experiências tem me ensinado sobre a relação entre teoria e política? A primeira lição (um pouco deprimente) é que a teoria acadêmica - incluindo meu próprio trabalho - tem tido relativamente pouco impacto direta ou indiretamente sobre o comportamento real do Estado. Estudiosos podem dizer para si mesmos que eles estão "falando a verdade para o poder", mas na maioria das vezes, os poderosos não escutam. Para observar um exemplo óbvio com o qual eu pessoalmente estive associado, o esforço feito por dois grupos proeminentes de estudiosos de segurança para se opor à decisão da invasão do Iraque em 2003 não teve nenhum impacto perceptível sobre a marcha em direção à guerra da administração Bush ou sobre muitos democratas que avidamente apoiaram a ação de Bush ${ }^{6}$.

Por que os escritos acadêmicos sobre relações exteriores têm uma relevância tão limitada? Para responder esta questão, deixe-nos primeiro considerar como a teoria pode ser capaz de contribuir, para então considerar por que seu impacto é relativamente modesto.

\section{0 papel da teoria no processo político}

Nós vivemos em um mundo de vertiginosa complexidade. A cada dia, os políticos devem tentar descobrir quais eventos devem ter mais atenção e quais itens podem ser deferido. Eles precisam selecionar os objetivos de longo prazo e escolher os instrumentos políticos que eles acreditam que irão promovê-los. Para fazer isso, eles dependem de um conhecimento puramente factual (por exemplo, como está a atual balança de pagamentos? Quanto de urânio enriquecido o Irã já tem?), mas também precisam de tipologias simples (por exemplo, poderes "revisionistas" versus poderes que visam manter o "status quo"), sobre "ditados populares e sensatos" derivados da experiência, ou sobre leis empíricas bem estabelecidas (por exemplo,

5 Um sinal de um discurso mais aberto foi a publicação, em 2012, de Peter Beinart. A discussão mais ampla de Beinart de que a administração de Obama falhou nos esforços para a paz também demonstra que o impacto do lobby não diminuiu.

${ }^{6}$ Juntamente com vários outros, eu ajudei a organizar e pagar por $1 / 4$ de página no The New York Times em Setembro de 2002, que dizia que "A Guerra com o Iraque NÃO é interesse nacional americano". Ver: http://www.bear-left.com/archive/2002/OP-Ed.pdf. Eu também assinei uma proeminente petição de oposição à guerra (JACKSON; KAUFMAN, 2007).
“Democracias não lutam umas com as outras"). E se eles estão conscientes disso ou não, os políticos invariavelmente usam, implícita ou explicitamente, teorias que construam um sentido na identificação das causas relacionais entre duas ou mais variáveis de interesse.

Porque as teorias contemporâneas de Relações Internacionais são relativamente fracas e os testes empíricos definitivos são ilusórios, os debates políticos frequentemente dependem dos apelos da competição teórica. Na década de 90, por exemplo, as discordâncias sobre como responder à guerra dos Bálcãs deveu-se em parte às teorias que competiam sobre as causas do conflito étnico ${ }^{7}$. Hoje, a competição entre as prescrições sobre como lidar com o crescimento da China repousa, em parte nas teorias rivais de política mundial, com realistas favorecendo ações preventivas designadas a conter a ambição chinesa, políticas liberais advogando pelo engajamento destinado a promover laços de interdependência e os construtivistas sociais procurando "socializar" a China dentro das normas e das instituições (KAUFMANN, 1996; STEDMAN, 1997 e SAMBANIS, 2000).

Estes debates são importantes porque ao confiar em falsas teorias, os políticos podem colocar os Estados em problemas profundos. Antes da Primeira Guerra Mundial, a admirável "teoria de risco" do alemão Alfred Von Tirpitz argumentava que a expansão naval colocaria a Marinha Real em risco e deteria a Grã-Bretanha de se opor às ambições germânicas. Em vez disso, esta política conduziu a Inglaterra a se alinhar com os inimigos da Alemanha. Este infame "domínio teórico" também ajudou a justificar o envolvimento caríssimo dos Estados Unidos na Indochina (Vietnã) e suas imprudentes intervenções na América Central, assim como as crenças ingênuas dos neo-conservadores sobre a facilidade com a qual a democracia poderia ser espalhada via força militar pavimentando o caminho em direção ao desastre no Iraque.

Esta conversa é também verdadeira, claro: boas teorias frequentemente produzem resultados políticos benéficos. A teoria de David Ricardo sobre o livre comércio ajudou a aumentar o crescimento da economia global e a teoria do controle nuclear desenvolvida na década de 50 informou muitos aspectos da política de defesa norte-americana e quase certamente reduziu o perigo da guerra nuclear.

\footnotetext{
7 Esta seção baseia-se no meu artigo "Theory and Policy in International Relations” (WALT, 2005).
} 
Do ponto de vista dos políticos, o que é uma boa teoria? Uma boa teoria deveria ser logicamente consistente e validada empiricamente (isto é, deveria caber em uma evidência disponível), deveria também ajudar aos políticos a compreender fenômenos que, de outro modo, seriam incompreensíveis (isto é o que nós entendemos por "poder explicativo" de uma teoria (MEARSHEIMER, 2010; CHRISTENSEN, 2006; JOHNSON, 2007)). As teorias são mais úteis para os políticos quando elas lidam com um fenômeno importante e quando elas contêm variáveis sobre as quais os políticos têm alguma influência (RAPAPORT, 1972). Finalmente, as teorias são mais úteis quando elas são expostas de forma clara. Ceteris paribus, uma teoria que seja difícil de entender demandará mais tempo para que seus potenciais usuários a compreendam e, em geral, se torna mais difícil de se verificar e testar.

Como a teoria pode ajudar os políticos a fazer seu trabalho de modo mais efetivo? Primeiro, a teoria pode ajudálos a diagnosticar novas situações à medida que elas surgem. Quando se pretende abordar se uma questão é recorrente ou se trata de um evento novo específico, os políticos precisam calcular exatamente que tipo de fenômeno eles estão confrontando. $\mathrm{O}$ impasse na negociação ocorre pela falta de confiança ou os protagonistas simplesmente estão muito longe de chegar a um acordo? $\mathrm{O}$ adversário procura alterar o status quo porque ele é ganancioso, tem excesso de confiança ou está ideologicamente inspirado ou porque ele é inseguro e está tentando melhorar sua fraca posição? Ao expandir o conjunto de interpretações possíveis, as teorias fornecem aos políticos um amplo conjunto de diagnósticos e pode ajudá-los a evitar encerrar o debate prematuramente ou criar formas perigosas de estereótipos.

Segundo, ao identificar as forças centrais que trabalham no sistema internacional - o que Kenneth Waltz chamou de "imagem de um reino" - as teorias podem ajudar os políticos a antecipar desenvolvimentos futuros ${ }^{8}$. Esta capacidade é especialmente valiosa no momento em

\footnotetext{
8 Stephen Van Evera (1997) se refere a tais teorias como sendo "prescritivamente ricas". Alexander George aconselhou os intelectuais a "incluir em seus projetos de pesquisa variáveis sobre os quais os políticos têm alguma influência". Ver "Foreword" (NINCIC; LEPGOLD, 2000). Teorias que não contêm variáveis manipuláveis podem ainda ser úteis se ajudar os políticos a entender o ambiente maior no qual eles estão operando. Por exemplo, sabendo se o sistema é bipolar ou multipolar pode ser valioso, mesmo se a pessoa não tem capacidade de alterar aquela condição.
}

que as circunstâncias mudam muito rapidamente e quando as projeções lineares do passado estão incertas. Para tomar um exemplo óbvio, seria tolice tentar prever a conduta da China no futuro olhando unicamente suas ações passadas ou mesmo seu comportamento recente porque os líderes chineses são suscetíveis de alterar suas preferências, bem como seus relativos aumentos de poder. Uma boa teoria, entretanto, poderia nos dizer como o deslocamento no equilíbrio do poder afetará o comportamento da China e ajudar os líderes a traçarem políticas designadas a evitar desenvolvimentos futuros perigosos.

Terceiro, a teoria é essencial para formular prescrições políticas porque todas as ações políticas dependem de, pelo menos, uma noção bruta de causalidade. Em outras palavras, os políticos selecionam as medidas A, B ou $C$ porque eles acreditam que elas produzirão o resultado desejado. A teoria ajuda os políticos a selecionar os objetivos, guiar a seleção dos instrumentos políticos e identificar as condições que devem ser atendidas para que estes instrumentos funcionem (WALTZ, 1979).

Quarto, a teoria também é uma crítica eficaz para a avaliação política. No sentido de determinar se uma política específica está funcionando, os políticos tem que identificar parâmetros que meçam o progresso em direção à (s) meta (s) estabelecida(s). A seleção destes parâmetros deveria estar teoricamente instruída, baseada no que nós achamos que sabemos sobre a relação causal envolvida na produção de um resultado desejado. Grandes estratégias baseadas na teoria realista tendem a enfatizar os parâmetros que medem as mudanças no poder relativo, por exemplo, enquanto uma estratégia oriunda de princípios liberais olham para os aumentos no intercurso econômico, níveis de participação democrática ou a ampliação e aprofundamento de instituições globais.

Finalmente, as teorias gerais de política internacional podem ajudar a nos proteger contra as várias formas de chauvinismo estereotipado. Em particular, as teorias realistas enfatizam a importância da segurança no mundo que carece de uma autoridade soberana e enfatizam como as forças estruturais "moldarão e empurrarão", mesmo Estados muito diferentes, em uma única direção. Porque eles reconhecem que todos os Estados devem confiar em seus próprios recursos para se defender, os realistas estão menos inclinados a demonizar os adversários e menos afeitos a ver a preparação militar do adversário como uma evidência de intenções agressivas. Os realistas 
também se colocam menos surpresos quando os Estados Unidos agem por caminhos que estão em desacordo com seus valores liberais ou seus alegados compromissos em avançar na defesa dos direitos humanos porque a teoria retrata a política internacional como um reino onde mesmo Estados poderosos devem às vezes comprometer ideais para melhorar sua segurança.

\section{0 impacto limitado da teoria}

Embora seja impossível formular política sem pelo menos uma teoria bruta (isto é, alguma noção do que causa o quê), mesmo teorias bem específicas de Relações Internacionais não parecem ter muito impacto na formulação política. Para os iniciantes, a maioria das teorias de Relações Internacionais procuram explicar tendências gerais ao longo do tempo e do espaço omitindo outras variáveis que podem ser relevantes para casos específicos sobre os quais os políticos estão lutando em um determinado momento. Nenhuma de nossas teorias existentes em nosso estoque tem grande poder explicativo e as ações específicas que os Estados tomam frequentemente são o produto de muitos fatores diferentes (poder relativo, tipo de regime, traços de liderança individual, etc.). Infelizmente, nós carecemos de um método claro que combine estas várias teorias ou decida qual exercerá o maior impacto em um caso particular.

O problema é agravado pelo contexto mais amplo em que cada política externa é feita. Cientistas sociais trabalham melhor quando os problemas podem ser definidos precisamente e analisados sistematicamente, isto é, quando a preferência dos atores é conhecida e constante, quando existem dados com os quais as conjunturas são testadas e quando o impacto das escolhas alternativas pode ser precisamente estimado. Entretanto, este raramente é o caso da conduta da política externa: a preferência dos atores é frequentemente obscura, eles frequentemente têm múltiplas estratégias disponíveis e os retornos das diferentes escolhas é frequentemente desconhecido. Relacionamentos não-lineares e efeitos endogênicos abundam, e preferências e percepções podem mudar sem aviso prévio. Mesmo os esforços cuidadosos em examinar o impacto de instrumentos políticos específicos, tais como programas de ajuda humanitária, sanções econômicas ou "mudanças impostas a regimes estrangeiros", estão repletos de efeitos de seleção que torna difícil estimar seu impacto causal.

Para tornar o assunto pior, os políticos e os teóricos têm agendas muito diferentes. Os teóricos buscam explicações gerais de comportamentos recorrentes, mas os políticos estão mais interessados em resolver problemas específicos que eles enfrentam hoje. Embora as tendências compreensivas possam ajudar os políticos a entender se seus objetivos serão fáceis ou difíceis, o que acontece, "na maior parte das vezes", é que isso não é tão pertinente quanto saber o que é mais provável de acontecer em um caso particular concreto. Sobretudo, os políticos estão frequentemente menos interessados em explicar tendências do que descobrir como superá-las. Como resultado, notou Arthur Stein, "o conhecimento experimental profundo domina as generalizações estatísticas e teóricas na formação da política"

Por último, mas não menos importante, o impacto da teoria é limitado ainda mais pela profissionalização dos sub-campos das Relações Internacionais e o crescente abismo entre a Torre de Marfim e o mundo político. Apesar de os intelectuais ainda migrarem para trabalhos na política de vez em quando, suas credenciais acadêmicas não ganham muito respeito nos círculos oficiais e até podem ser vistas como uma deficiência (STEIN, 2000). Eles podem também aprender que os políticos geralmente valorizam lealdade e efetividade burocrática muito mais do que prestigiosas distinções acadêmicas ou novidades teóricas.

Sobretudo, como a maior parte da ciência política, a acadêmica contemporânea de Relações Internacionais é escrita para os seus próprios pares e não se destina para um público maior, o que é uma das razões por que ela é altamente impenetrável e frequentemente preocupada com tópicos triviais e limitados. Jovens intelectuais entendem que as novidades teóricas e a sofisticação metodológica são muito mais valorizadas do que um conhecimento profundo de uma área política. De fato, existe um claro preconceito contra a mais recente teoria política contemporânea. Aqueles professores sem estabilidade são

\footnotetext{
9 Este foi o objetivo central do trabalho de George sobre a teorização da "relevância política", bem como o volume da então chamada teoria de médio alcance que tendia a produzir generalizações sobre o impacto de instrumentos políticos específicos como dissuasão de ameaças, sanções econômicas, diplomacia coercitiva, etc. Veja seu "Theory for Policy in International Relations” (GEORGE; SMOKE, 1974).
} 
rotineiramente advertidos a não desperdiçar seu tempo escrevendo para o público da política por medo de serem considerados "não intelectuais". Porque o trabalho que pode ser útil para os políticos traz poucas recompensas, não é de surpreender que os intelectuais instalados nas universidades raramente tentam produzi- $-\mathrm{o}^{10}$.

Em vez disso, o fosso entre teoria e política foi preenchido pelo crescimento de uma variedade de think thanks, consultores e outros grupos quase acadêmicos que agora dominam a vida intelectual na maioria das capitais do mundo, e especialmente em Washington D.C. Os políticos já não necessitam consultar os intelectuais instalados nas universidades para o aconselhamento sobre problemas globais prementes porque não há escassez de pessoas dentro de Washington que estão satisfeitas em fazer este trabalho e são pagas para fazer exatamente isso. Estas organizações podem fornecer orientações úteis, mas obviamente existem desvantagens para a sua proeminência crescente. A maioria dos think thanks sediados em Washington tem uma agenda ideológica - frequentemente moldada pelos seus financiadores - e seus produtos de pesquisas estão sujeitos a muito menos modelos rigorosos. Eles também carecem de habilitação de procedimentos elaborados, incluindo revisão dos pares que as universidades dependem para tomar decisões pessoais. Os políticos podem ficar desinteressados e fora das recomendações que abordem preocupações imediatas, se não estiverem bem fundamentadas ou pensadas.

Isto não quer dizer que os intelectuais acadêmicos não tenham nenhum impacto. Às vezes, os teóricos de Relações Internacionais dão à comunidade política e ao mundo em geral um vocabulário que molda discursos e pode exercer efeitos súbitos na formação política. Conceitos como "interdependência", "choque de civilizações", "bipolaridade", "ameaça de uso da força", "soft Power", etc. formam parte da linguagem do debate político, influenciando decisões de forma indireta. Intelectuais também podem tirar partido das proteções de mandato para enfrentar matérias tabus ou particularmente controversas e

\footnotetext{
${ }^{10}$ Krasner oferece uma notável anedota: "Eu fiz isso uma vez e foi realmente estúpido. Eu disse: $\mathrm{Eu}$ tenho um $\mathrm{PhD}$ e eu sei sobre isso." Isso é um comentário completamente inútil. Ninguém se preocupa com as suas credenciais... (sendo tratado como um professor nos círculos políticos) foi uma coisa ruim porque as pessoas achavam que você era um snob." Citado por Lisa Trei (2003).
}

podem ter sucesso ao abrir um debate sobre temas anteriormente negligenciados.

Ainda, nos Estados Unidos, pelo menos, os teóricos de Relações Internacionais raramente desafiam tabus e raramente possuem algum impacto na política a menos que eles deixem sua vida acadêmica e trabalhem diretamente no governo. Nossa impotência coletiva como campo não deve nos surpreender: os Estados Unidos são o país mais poderoso do mundo e sua burocracia de política externa é enorme, bem enraizada, permeada por poderosos grupos de interesse e outras partes interessadas. Ela também tem um sistema de governo dividido com muitos pontos de veto, a partir dos quais fazer inovação política é extremamente difícil. Sob estas condições, seria ingênuo acreditar que um livro acadêmico ou um artigo ou mesmo toda uma série deles - poderia conduzir o leme do Estado em uma direção totalmente nova por si só.

Para ter um impacto significativo na política requer ou envolvimento direto ou engajamento político continuado, atividades que muitos intelectuais ou nunca se interessaram ou não estão preparados para perseguir. Voltando a 1950, por exemplo, Albert Wholstetter e seus colegas deram dúzias de entrevistas apresentando os resultados da RAND Corporation, os famosos "estudos fundamentados", em um esforço finalmente exitoso de convencer o aparato militar a adotar suas recomendações ${ }^{11}$. Similarmente, a campanha prolongada dos neoconservadores para a guerra com o Iraque - que agora nós sabemos foi construída em cima de erros factuais, análise tendenciosa e falsas teorias - começou cuidadosamente em 1998, mas não deu frutos até cinco anos posteriores. Persistentemente, não perspicazmente, é a fonte original da influência política na formação de políticas governamentais.

Esta situação tem de ser desconcertante para aqueles de nós que estão ambos dedicados para a "vida da mente" e ainda interessados em usar o conhecimento para construir um mundo melhor. Nós ainda podemos

${ }^{11}$ Como Adam Przeworski observou a alguns anos atrás, "toda a estrutura de incentivos na academia norte-americana trabalha contra grandes riscos, sejam eles intelectuais ou políticos. Estudantes de pós-graduação e professores assistentes aprendem a empacotar suas ambições intelectuais dentro de artigos publicáveis em algumas revistas e fugir de qualquer coisa que possa parecer como uma postura política (MUNCK; SNYDER, 2004). 
esperar em fazer avançar este objetivo através de nossas aulas, e como anteriormente notado alguns intelectuais terão um impacto direto por meio de seus próprios trabalhos no governo. Haverá ocasionalmente momentos quando um intelectual fornece uma nova perspectiva ou uma abordagem analítica que usa a imaginação de quem está no poder, frequentemente porque ela aborda as necessidades percebidas naquele momento. Mas para a maioria dos membros da disciplina o objetivo de "falar a verdade ao poder" será cada vez mais distante.

A despeito destas limitações, os intelectuais acadêmicos - incluindo os teóricos de Relações Internacionais - tem pelo menos três papéis úteis a desempenhar no discurso público mais amplo sobre assuntos internacionais. Primeiro, aqueles que mais longa e duramente tem pensado sobre a natureza da política no mundo moderno pode ajudar seus concidadãos a entender nosso mundo "globalizado". Comumente, as pessoas muitas vezes sabem muito sobre assuntos locais, mas entender o que está acontecendo no exterior requer a confiança no conhecimento de especialistas. Por esta razão, acadêmicos instalados nas universidades devem ser fortemente encorajados a escrever e falar para públicos cada vez maiores em vez de se envolver unicamente em um diálogo uns com os outros.

Segundo, um envolvimento da comunidade acadêmica é um contrapeso essencial aos esforços do governo em manipular a percepção pública. Os governos tem um enorme acesso à informação do que a maior parte (?) dos cidadãos, especialmente no que se refere à política externa e de defesa e os funcionários públicos rotineiramente exploram estas assimetrias de informação para avançar suas próprias agendas. Porque os funcionários do governo são falíveis, a sociedade necessita de vozes alternativas para desafiar suas racionalidades e sugerir diferentes soluções. Os intelectuais acadêmicos estão protegidos por mandato e não dependem diretamente do apoio do governo para sua subsistência. Então eles estão singularmente em posição de desafiar narrativas dominantes e sabedorias conservadoras. Por estas razões, uma comunidade acadêmica engajada e diversa é o que completa as políticas democráticas saudáveis. Terceiro, a comunidade acadêmica também pode oferecer um modelo útil de debate construtivo. Apesar de algumas disputas intelectuais serem às vezes acaloradas, elas raramente descem ao nível de um ataque ad hominen ou assassinato de caráter que cada vez mais caracteriza o discurso político hoje. De fato, intelectuais que utilizam estas táticas em um artigo acadêmico muito provavelmente se desacreditariam mais do que seus alvos. Ao trazer normas do discurso acadêmico dentro da esfera pública, intelectuais poderiam ajudar a restaurar um pouco de civilidade que sido perdida na vida pública contemporânea.

Como é que estes milagres podem ser realizados? Eu não tendo ilusões criar alguma espécie de reino filosófico onde as regras acadêmicas e os trinta anos em três universidades diferentes, três diferentes think tanks tenham me convencido que tal mundo quase que certamente não teria um avanço. Mas os intelectuais de Relações Internacionais deveriam realmente estar orgulhosos com o fato de tão poucas pessoais se preocupam sobre o que nós temos a dizer?

Fará um pouquinho bem implorar aos políticos e ao público prestar mais atenção em nós. O único remédio é produzir trabalhos que seja tanto academicamente rigoroso, mas também potencialmente útil para aqueles encarregados de tomar decisões políticas. O que é necessário, portanto, é um esforço consciente para alterar as normas vigentes e incentivar a comunidade acadêmica. Este objetivo não é tão rebuscado quanto pode parecer, em relação às nossas normas profissionais que não são nem fixas e nem ordenadas divinamente. Em vez disso, os membros do nosso próprio campo determinam coletivamente as normas que governam nossa empresa. Como uma comunidade em grande parte autopoliciada, podemos decidir quais características nós damos mais valor e não existem razões porque à relevância política e ao engajamento publico não poderia ser dado um peso maior.

\section{0 que deve ser feito?}

Se a comunidade de intelectuais das Relações Internacionais decidir que está cansada de ser ignorada, existem um número de passos práticos que poderiam ter maior relevância, a saber ${ }^{12}$ :

${ }^{12} \mathrm{O}$ Estudo RAND examinou a questão de como implantar bombardeiros americanos para otimizar tanto sua sobrevivência no caso de um ataque soviético como sua efetividade no curso de uma guerra. Vale a pena relembrar que Wohlstetter não era um acadêmico instalado em uma universidade à época (acho que mais trade ele lecionou na Universidade de Chicago), mas sim um empregado de um think-tank financiado pelo governo. 
1. Dar maior peso para o Impacto no mundo real no desenvolvimento das decisões.

Em vez de focar quase que inteiramente nos jornais profissionais revisados pelos pares e monografias, promover comitês que também poderiam conduzir avaliações sistemáticas das contribuições de um membro da faculdade para o discurso do público maior ${ }^{1314}$. Além de medir o número de citações, por exemplo, os comitês de avaliação poderiam também acompanhar notícias ou sucessos dos blogs de um candidato à vaga de trabalho. $\mathrm{E}$ em vez de confiar apenas na avaliação de outros intelectuais, estes mesmos comitês poderiam também solicitar avaliações de políticos que trabalham em campos relevantes. Descobrir que o trabalho de um colega iniciante tem exercido um impacto maior sobre como os políticos pensam sobre uma questão é certamente relevante para uma avaliação de seu valor a longo prazo.

2. Encorajar Associações profissionais de respeitável Impacto público

No momento, a American Political Science Association tem dúzias de prêmios para livros, artigos e papers em vários campos e subcampos. Dar um prêmio "em reconhecimento de notável serviço público! E outro para a realização da carreira "para a arte de governar". Se nós queremos encorajar intelectuais a atingir grandes impactos, criando um ou dois prêmios a mais destinados a recompensar (honrar) tais realizações não parece nada excessivo.

3. Facilitar aos jovens intelectuais a obter mais experiência política

Para estimular os jovens intelectuais a aprender como funciona o mundo real, os departamentos poderiam tornar mais fácil para eles trabalhar no governo ou em outra área política relevante. Por exemplo, mais uni-

${ }^{13}$ Uma apresentação mais extensa destas ideias pode ser encontrada em Walt (2011).

${ }^{14}$ Como Bruce Jentleson (2000) tem escrito: "Should it really be the case that a book with a major university press and an article or two in a (refereed) journal ...can almost seal the deal for tenure, but books with even a major commercial house count so much less and articles in journals such as Foreign Affairs count little if at all? ... (T)he argument is not about padding publications counts with op-eds and other such commentaries, but it is to broaden evaluative criteria to better reflect the type and range of writing of intellectual import". Veja seu texto: "In Pursuit of Praxis: Applying International Relations Theory to Foreign Policymaking". versidades poderiam adiar a posse se um professor universitário iniciante quisesse passar um ano trabalhando no governo ou para uma organização não-governamental. Esta política criaria mais intelectuais que verdadeiramente saberiam como o governo trabalha e provavelmente eles produziriam trabalhos que seriam acessíveis e relevantes para os políticos. Porque a maioria dos estudantes se preocupa com o mundo real e tem interesse limitado no vazio escolástico, esta política ajudaria também a criar melhores professores.

4. Engajar os Políticos nos Processos de Pesquisa

A capacidade de definir e perseguir sua própria agenda de pesquisa é um elemento chave da liberdade acadêmica. Este princípio não deve estar comprometido, mas intelectuais devem estar mais dispostos a ouvir os praticantes quando decidem que assuntos irão explorar. Além disso, para derivar novos tópicos de um vazio de existência intelectual, não há nada a perder se ocasionalmente se perguntar aos não-intelectuais que tipos de conhecimento eles gostariam de ter. Nós podemos nos surpreender pela quantidade de boas questões eles trazem.

5. Convencer a administração universitária a valorizar as contribuições ao mundo real

Reitores, decanos e diretores podem promover estas metas bem como premiar departamentos cujos membros falam contribuições substanciais à espera pública e pelos recursos retidos na fonte daqueles que estão presos no "culto da irrelevância". A proposta não é encorajar os departamentos a se transformar em pelotões ansiosos perseguidores de manchetes de analistas políticos para fazer sucesso no circuito de talk-show, mas em vez disso, promover uma comunidade mais heterogênea em todos os níveis da academia.

6. Ampliar a discussão da ética e da Responsabilidade acadêmica

No momento, a ética profissional geralmente gira em torno de tópicos como plágio, liberdade acadêmica e abusos de poder na forma de perseguição sexual ou no tratamento de indivíduos humanos. Estas são questões importantes, mas nós devemos também estimular os estudantes a pensar longa e duramente sobre os débitos que os intelectuais estão em dívida com a sociedade que os 
apoia e a questão de se nós temos uma responsabilidade ética maior no uso do nosso conhecimento e treinamento para o melhoramento da sociedade. Esta discussão deve também focar as armadilhas éticas que podem afetar os intelectuais que se tornam diretamente engajados na pesquisa de relevância política e especialmente quando fundos ou outros recursos de compensação estão envolvidos

\section{Conclusão}

Como Keynes famosamente observou "mesmo o mais prático dos homens práticos de negócios é frequentemente escravo das ideias de alguns economistas mortos há muito tempo". É possível que os intelectuais de Relações Internacionais exerçam o mesmo impacto duradouro, mas eu estou inclinado a duvidar disso. Os políticos parecem cada vez menos interessados no que nós temos a dizer, parcialmente porque eles estão muito ocupados lidando com seus problemas diários, mas também porque nós tendemos a fazer perguntas que eles não estão preocupados e nós oferecemos respostas que eles acham que não precisam. Se os intelectuais querem ocupar um papel mais ativo e construtivo em assuntos mundiais, em resumo, o conteúdo de nossa intelectualidade deve mudar.

Para encorajar esta mudança, nós teremos que modificar os critérios de méritos dentro da própria disciplina e dar um peso maior de relevância ao mundo real. Sem esta mudança, podemos esperar do mundo exterior é dar cada vez menos atenção ao que nós temos a dizer. Isto não me parece apenas uma abdicação das nossas responsabilidades como intelectuais e cidadãos, mas é um mau presságio para o futuro da própria disciplina, pois se não estamos produzindo conhecimento útil que possa ajudar a sociedade resolver problemas comuns, porque os estudantes devem se matricular em nossos cursos e por que as universidades devem continuar alocando os esparsos recursos para os nossos departamentos?

\section{Referências}

BEINART, Peter. The Crisis of Zionism. New York: Times Books, 2012.

CRAIG, Gordon A. Germany 1866-1945. Oxford: Oxford University Press, 1978.
CHRISTENSEN, Thomas J. Fostering Stability or Creating a Monster?: the Rise of China and US Policy Toward East Asia. International Security, Baltimore, Maryland, Estados Unidos, v. 31, n. 1, p. 81-126, Summer 2006.

EVERA, Stephen Van. Guide to Methods for Students of Political Science. Ithaca, NY: Cornell University Press, 1997.

GEORGE, Alexander. Theory for Policy in International Relations. In: GEORGE, Alexander; SMOKE, Richard. Deterrence in American Foreign Policy: Theory and Practice. New York, Columbia University Press, 1974.

JACKSON, Patrick Thaddeus; KAUFMAN, Stuart. Security Scholars for a Sensible Foreign Policy: a Study in Weberian Activism. Perspectives On Politics. Cambridge, Reino Unido, v. 5, n. 1, p. 95-103, mar. 2007.

JENTLESON, Bruce. In Pursuit of Praxis: Applying International Relations Theory to Foreign Policymaking. In: NINCIC, Miroslav; LEPGOLD, Joseph (Ed.). Being Useful: Policy Relevance and International Relations Theory. Ann Arbor: University of Michigan Press, 2000.

JOHNSON, Alastair Iain. Social States: China in International Institutions, 1980-2000. Princeton: N.J.; Princeton University Press, 2000.

KAUFMANN, Chaim. Possible and Impossible Solutions to Ethnic Civil War. International Security, Massachusetts, Estados Unidos, v. 20, n. 4, 1996.

MEAD, Lawrenc. Scholasticism in Political Science. Perspectives on Politics. Cambridge, Reino Unido, v. 8, n. 2, p. 453-464, jun. 2010.

MEARSHEIMER, John. The Gathering Storm: China's Challenge to US Power in Asia. The Chinese Journal of International Politics. Oxford, Reino Unido, v. 3, 2010.

MEARSHEIMER, John J; WALT, Stephen M. The Israel Lobby. London Review of Book, London, v. 28, No. 6, p. 3-12, 23 mar. 2006.

MEARSHEIMER, John J; WALT, Stephen M. The Israel Lobby and U.S. Foreign Policy. New York: Farrar, Straus and Giraux, 2007.

MUNCK, Gerald; SNYDER, Richard. What Has Comparative Politics Accomplished?. APSA-CP Newsletter. Notre Dame, Indiana, Estados Unidos, v. 15, n. 2, p. 26-31, 2004.

NEWSOM, David Newsom. Foreign Policy and Academia. Foreign Policy. Washington D.C, Estados Unidos, v. 101, p. 52-67, 1995-1996. 
NINCIC, Miroslav; LEPGOLD, Joseph (Ed.). Being Useful: Policy Relevance and International Relations Theory. Ann Arbor: University of Michigan Press, 2000.

RAPAPORT, Anatol. Explanatory Power and Explanatory Appeal of Theories. Synthese, Dordretch, Holanda, v. 10, p. 321-342, 1972.

SAMBANIS, Nicholas. Partition as a Solution to Ethnic War: an Empirical Critique of the Theoretical Literature. World Politics, v. 52, n. 4, p. 437-483, 2000.

STEDMAN, Stephen. Spoiler Problems in Peace Processes. International Security, Massachusetts, Estados Unidos, v. 22, n. 2, p. 5-53, 1997.

STEIN, Arthur. Counselors, Kings, and International Relations: from Revelations to Reason, and Still No PolicyRelevant Theory. In: NINCIC, Miroslav; LEPGOLD, Joseph (Ed.). Being Useful: Policy Relevance and International Relations Theory. Ann Arbor: University of Michigan Press, 2000.

TREI, Lisa. Does the Academic Study of International Relations Matter in the Real World of Policy?. Stanford News Service, Stanford, Estados Unidos, January 27, 2003. Disponível em: <http://news.stanford.edu/pr/03/ krasner129.html>.
WALT, Stephen M. The Origin of Alliances. Ithaca: Cornell University Press, 1987.

WALT, Stephen M. Revolution and War. Ithaca: Cornell University Press, 1996.

WALT, Stephen M. Taming American Power: the Global Response to U.S. Primacy. New York: W.W. Norton, 2005a.

WALT, Stephen M. Theory and Policy in International Relations. Annual Review of Political Science, Palo Alto, California v. 8, Annual Reviews, p. 23-48, 2005b.

WALT, Stephen M. International Affairs and the Public Sphere. Social Science Research Council, 2011. Disponível em: $\quad<$ http://publicsphere.ssrc.org/walt-internationalaffairs-and-the-public-sphere/ $>$.

WALTZ, Kenneth. Theory of International Politics. Reading-MA: Addison-Wesley, 1979.

WALTZ, Kenneth. "War with Iraq in not in America's National Interest”. Ver: http://www.bear-left.com/ archive/2002/OP-Ed.pdf 


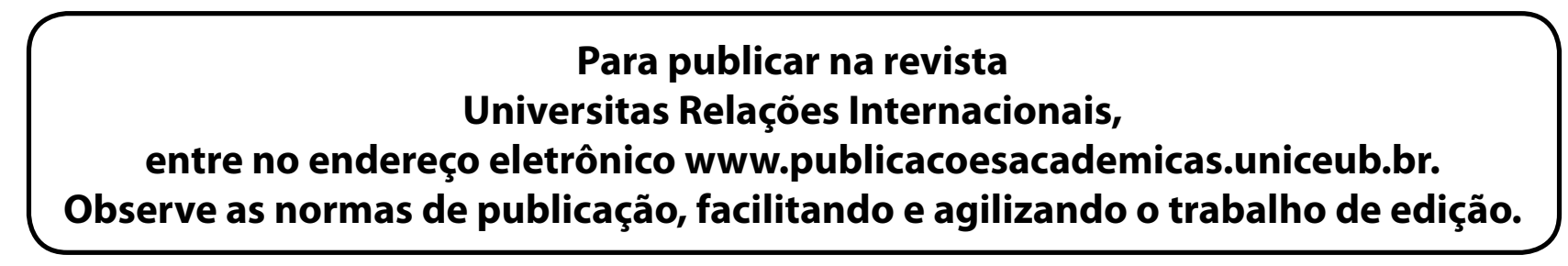

